\title{
López Nicolás, José Manuel (2016): Vamos a comprar mentiras. Alimentos y cosméticos desmontados por la Ciencia. Palencia: Cálamo. 361 pp. ISBN: 978-84-96932-95-1.
}

La ciencia cuenta sin duda con una gran consideración social. Periódicamente se publican encuestas en las que se refleja que médicos y científicos se encuentran entre los profesionales mejor valorados, lo cual no deja de ser irónico: casi nadie conoce a un científico. Esto nos lleva a plantearnos que dicha valoración positiva no puede obedecer a afinidades personales fruto de la experiencia cotidiana. Tampoco puede serlo por un conocimiento detallado de la actividad que desarrollan. La cultura científica de los españoles es discreta tal y como reconocemos nosotros mismos (ver encuesta de la Fundación Española para la Ciencia y la Tecnología, FECyT) por lo que solo puede ser fruto de una consideración positiva genérica sobre los beneficios que el desarrollo científico aporta a la sociedad. Animados por un entusiasmo incansable al desaliento, podemos ver esta combinación de valoración y desconocimiento como una oportunidad, otra mas, para recuperar el tiempo tantas veces perdido y situar a la Ciencia en el lugar que le corresponde en una sociedad desarrollada. Desgraciadamente esto no ha sido la tónica habitual. Nuestros presupuestos dedicados a estos aspectos han estado siempre a la cola de Europa, ni que decir de la aportación empresarial, tanto cuando no había crisis como con ella. Hablamos de cambio del modelo productivo pero no tenemos interiorizada la máxima de que un país no hace Ciencia porque es rico sino que es rico porque hace Ciencia. Mucha retórica pero seguimos en el que inventen ellos y claro, si los poderes públicos no son capaces mediante el sistema educativo de enriquecer el bagaje científico de la sociedad esta queda indefensa frente a la manipulación

Sobre esta manipulación trata precisamente el libro que comentamos hoy: Vamos a comprar mentiras, alimentos y cosméticos desmontados por la Ciencia, de José Manuel López Nicolás. El autor es doctor en Química, profesor de Bioquímica y Biología Molecular en la Universidad de Murcia y autor del blog Scientia. Su intención al escribir esta obra ha sido denunciar en voz alta los abusos que está sufriendo el ciudadano y que repercuten en su bolsillo pero, y esto es mas importante, en su salud. Bien podemos decir que lo consigue ya que con un lenguaje claro, perfectamente accesible a cualquier persona sin formación científica, pero con rigor nos aporta numerosos ejemplos para entender las estrategias de marketing empleadas por las empresas. Muestra, en definitiva, cómo se retuercen o inventan las evidencias científicas con el fin de vender bienes, como los alimentos y los cosméticos, aprovechándose de la buena valoración y del desconocimiento de la opinión pública a los que antes nos referíamos.
El presente ensayo se estructura en dieciséis capítulos mas un prólogo a modo de declaración de intenciones y un epílogo. Comienza explicando aspectos que van a resultar fundamentales en el texto como lo que son los alimentos funcionales para pasar a los cometidos de la Autoridad Europea de Seguridad Alimentaria (EFSA en sus siglas en inglés). Dicha agencia nació como una autoridad independiente encargada de proteger a los consumidores aumentando su confianza y las garantías ofrecidas por los alimentos. Con el fin de poner coto a las agresivas campañas comerciales que prometían todo tipo de beneficios se elaboró una reglamentación a la que debía someterse toda empresa alimenticia para poder publicitar que sus productos promueven alguna propiedad fisiológica mas allá de su carácter nutricional. López Nicolás nos describe los elementos mas significativos de dicho reglamento y qué tipos de productos han sido aprobados por la EFSA y cuáles no, principalmente por la falta de estudios en humanos que avalen las propiedades observadas in vitro o con animales. Este es un aspecto fundamental que debería preocuparnos. Cada vez es mas común que resultados observados en las condiciones controladas de un laboratorio sean explotados sin que exista la menor prueba de que vaya a funcionar en el ser humano. Si hay quienes encuentran resquicios legales para poder hacerlo en el mundo de los productos sanitarios, saltándose la inexistencia de ensayos clínicos que avalen sus afirmaciones (el mundo de las células madre adultas es paradigmático a este respecto), en la alimentación y cosmética el descaro alcanza lo indecible.

La manera en la que las empresas alimentarias pueden hacerlo contra la regulación de la EFSA es lo que describe el autor en los siguientes siete capítulos. En ellos podemos encontrar ejemplos de marcas conocidísimas que emplean lo que el autor denomina acertadamente estrategia del asterisco. Esta consiste en publicitar un compuesto estrella por el que pagamos un precio extra al atribuirle supuestas virtudes fisiológicas (ayuda a las defensas, o al tránsito intestinal...) que la EFSA no tiene acreditadas. Junto al nombre del producto aparece un asterisco que nos remite a la trasera del envase, a menudo con un tipo de letra casi ilegible, donde se afirma que ese alimento contiene cierto porcentaje de un mineral o vitamina comunes y que podemos encontrar en cualquier otro alimento (y más barato) para los cuales la EFSA sí permite realizar la afirmación saludable publicitada. La descripción de esta práctica, tan poco ética, es completada por el autor por otras que se aprovechan de la mala prensa de sustancias como el colesterol o la lactosa. López Nicolás realiza una importante labor al 
explicar la importancia de estas sustancias en nuestra vida deshaciendo mitos que sirven a las empresas para vender productos de utilidad más que discutible para la inmensa mayoría de los consumidores. El mismo espíritu informativo impregna capítulos como los dedicados a las bebidas energéticas, para las que el autor reclama una necesaria regulación hoy inexistente, o a los colorantes, humorísticamente titulado Con colorantes, con conservantes, con mucha química y otras porquerías. La quimiofobia de sectores de la sociedad es un serio problema que demanda de todos una lucha activa al no ser más que una forma de ignorancia que puede tener graves consecuencias, no solo para el bolsillo de los ciudadanos sino para su salud. Es triste ver cómo ciertas empresas se aprovechan de la incultura científica, azuzada por una legión de creadores de bulos, para hacer caja mediante estrategias burdas como cambios de nombre 0 afirmaciones que no pasan de ser medias verdades claramente contrarias a los reglamentos comunitarios y que contribuyen a la desinformación general. Los ejemplos expuestos en el libro resultan significativos.

No se puede acusar al autor de corporativismo, al contrario. No cabe duda de que los investigadores tenemos una responsabilidad a la hora de exponer al público de manera inteligible nuestros conocimientos, pero no lo podemos hacer dejándonos arrastrar por cantos de sirena comerciales. A este respecto, López Nicolás critica duramente a las fundaciones y organismos de investigación que prestan su aval en forma de logo como parte de la estrategia comercial de productos innecesarios o no suficientemente probados a cambio de no se sabe qué. El caso del Revidox y el CSIC es un claro ejemplo que le sirve al autor para explicar lo que realmente sabemos del resveratrol y su relación con la ingesta diaria de vino. Que haya productos como el citado que se vendan en farmacias, con el aval que eso supone, debería hacernos reflexionar sobre los límites éticos que no deben ser traspasados. Es evidente por todo lo anterior que no existen mecanismos de autocontrol de la publicidad eficientes al estar en manos de las mismas empresas que cometen los abusos, por ello resulta tan imprescindible la colaboración de los grandes actores de la información: los medios de comunicación. A ellos dedica un capítulo animándolos a no ser vehículos de incultura científica mediante titulares alarmistas, información no contrastada, publicidad encubierta o fomento de la pseudociencia. Desgraciadamente a los casos expuestos en el presente ensayo podemos añadir otros muchos de un problema que por su magnitud resulta cotidiano.

Los siguientes cuatro capítulos se centran en los productos cosméticos. En este caso, las afirmaciones de base supuestamente científica que realizan las casas comerciales rayan con lo delirante. Acertadamente, el libro nos presenta el marco legal en que ha de desenvolverse la publicidad de estos productos. Este resulta variado, si bien entre las distintas normas sobresale el reglamento de la UE 655/2013. Sin lugar a dudas se trata de una norma mucho más estricta que la alimentaria, pero se encuentra ante un problema fundamental que la transforma en ineficaz: no existe agencia europea alguna que se encargue de velar por su cumplimiento $y$, añade el autor, las autoridades nacionales miran para otro lado. López Nicolás describe de modo ameno e instructivo los casos escandalosos de cremas con ADN, activadores de la juventud, células madre o sirtuinas, entre otros, que contradicen de manera flagrante dicha normativa al no existir elementos de prueba que avalen sus afirmaciones. Es imposible no pensar en lo curioso que resulta que, mientras los alimentos genéticamente modificados generan un rechazo, no existe queja alguna ante los cosméticos que pretenden que integremos ADN extraño. Semejante contradicción es una evidencia más de la falta de solidez en la formación científica de la población de la que se abusa impunemente. Miles de investigadores trabajan en todo el mundo con la ilusión de realizar aportaciones beneficiosas, que de paso sirven para promocionarles en sus carreras, y sin embargo nos encontramos con que las empresas de cosmética afirman realizar descubrimientos fabulosos como activar genes de la juventud y a nadie parece extrañarle que no se publiciten del mejor modo posible: ganando un premio Nobel.

Junto a fantásticas afirmaciones no demostradas, la cosmética comparte otros vicios con las empresas alimenticias y López Nicolás da buena cuenta de ello. Casos como la promoción de la quimiofobia en desodorantes y cremas hidratantes, la estrategia del asterisco en zumos avalados por el CSIC, o en compuestos indicados para la firmeza de la piel o el bronceado, son explicados con claridad y sentido del humor.

Para terminar el autor lo hace con dos capítulos oportunamente titulados Cómo evitar un fraude en cinco cómodos pasos y Los siete pecado(re)s capitales del fraude pseudocientífico donde nos resume cuál debería ser la manera sensata de actuar para reconocer cuándo se nos quiere vender algo que no corresponde con lo publicitado y a quienes (de un modo u otro, todos) corresponde ejercer un papel mas activo en el control de estos asuntos.

En definitiva, Vamos a comprar mentiras es una obra que nos enseña a ser consumidores, lo que es lo mismo, ciudadanos, responsables. Por realizar una crítica podríamos decir que la edición debería haber sido algo más cuidada ya que ciertos cuadros y gráficas no tienen la suficiente definición. Quizás la editorial no sospechaba el éxito que está teniendo pero, dado que ya va por la séptima edición, quizás podría mejorarse este aspecto. En cualquier caso, lo dicho no altera para nada lo sustancial: el ensayo es altamente recomendable y debería ser de lectura obligada, al menos en la enseñanza secundaria, último momento en el que a alguien se le puede obligar a leer algo. Sin duda, nadie está exento de la influencia de la publicidad pero los ciudadanos necesitamos herramientas para poder defendernos del uso 
fraudulento de actividades valoradas positivamente. Este libro resulta fundamental para ello.

\section{José Antonio Uranga Ocio Universidad Rey Juan Carlos} jose.uranga@urjc.es

Recibida: 02-03-2018 Aceptada: 19-03-2018

(c) (1) (\$) 